\title{
Lewis acids immobilized in ionic liquid - application for the acetal synthesis
}

\author{
Ewa Janus \\ West Pomeranian University of Technology, Szczecin, Department of Chemical Organic Technology, ul. Pułaskiego 10, \\ 70-322 Szczecin, Poland, e-mail: ejanus@zut.edu.pl
}

\begin{abstract}
Catalytic systems composed of metal chloride $\left(\mathrm{InCl}_{3}, \mathrm{ScCl}_{3}, \mathrm{YCl}_{3}, \mathrm{YbCl}_{3}, \mathrm{LaCl}_{3}, \mathrm{BiCl}_{3}, \mathrm{ZnCl}_{3}\right.$ and $\left.\mathrm{CuCl}_{3}\right)$ and 1-butyl-1-methylpyrrolidinium bis(trifluoromethylsulfonyl)-imide, $\left[\mathrm{C}_{1} \mathrm{C}_{4} \mathrm{Pyrr}\right]\left[\mathrm{NTf}_{2}\right]$ as ionic liquid were prepared. Catalytic activity of all the systems were compared in acetalization reaction between cyclohexanone and triethyl orthoformate. 1,1-Diethoxycyclohexane were formed with high yield and the selectivity at $0^{\circ} \mathrm{C}$ within 5 minutes. Selected metal chlorides immobilized in ionic liquid were recycled 5 times without a decrease in their activities.
\end{abstract}

Keywords: acetal formation, ionic liquid, Lewis acid, 1,1-diethoxycyclohexane.

\section{INTRODUCTION}

The acetalization reaction is one of essential reactions for the protection of carbonyl group in the multi-step organic synthesis. Moreover, the products of the said reaction - acetals are important compounds with various practical applications. They are widely used as flavors and fragrances in the cosmetic and food industry ${ }^{1,2}$. What is more, they serve as: components of lubricants used in metal processing ${ }^{3}$, diesel fuel additives ${ }^{4}$, impregnating substances (giving hydrophobicity) which are used in the paper and textile industry ${ }^{5}$. Acetals derived from carbohydrates (sorbitol, xylitol) have found their use as gelling and thickening agents e.g. in fluid detergent compositions ${ }^{6}$. Ribonucleoside cyclic acetals are used as precursors and prodrugs of inhibitors of hepatitis $\mathrm{C}$ virus replication ${ }^{7}$.

Most methods for acetal synthesis are based on the reaction of carbonyl compound, with either alcohol or ortoester ${ }^{8}$. There are also other methods, involving transacetalization ${ }^{\mathbf{9}}$, addition of alcohols to alkynes ${ }^{\mathbf{1 0}}$, or alcohol reaction with O-allyl systems ${ }^{11}$. The catalysts used in these reactions are acidic in nature. Most of them are protonic acids, their acid salts, Lewis acids in metal chlorides and trifluoromethanesulfonates form, as well as transition metal complexes. From the analysis of the research papers on the subject it can be concluded that the main problem connected with acetalization reaction is the lack of possibility of recovering and recycling the catalyst. This issue is particularly important with reference to the more expensive metallic catalysts. In recent years, ionic liquids have become a very promising solution in this respect. We know of the processes in which the catalyst is immobilized in an ionic liquid and may be used multiple times without decreasing its activity ${ }^{12,13}$. However, acetals synthesis in ionic liquids still remains a poorly explored subject, especially in the context of the use of ionic liquids in combination with metallic catalysts ${ }^{14}$.

The studies presented in this paper include preparation of catalyst systems composed of ionic liquid and metal chloride as the Lewis acid, determination their activity, as well as possibilities of recycling in a model acetalization reaction. Cyclohexanone and triethyl orthoformate are the substrates of the model reaction. 1-Butyl-1-methylpyrrolidinium bis(trifluoromethylsulfonyl)imide $\left[\mathrm{C}_{1} \mathrm{C}_{4} \mathrm{Pyrr}\right]$ $\left[\mathrm{NTf}_{2}\right]$ was selected as the ionic liquid for the studies.
This choice was motivated by the low proton-acceptor properties of this ionic liquid $(\beta=0,2)$ which are essential for keeping the activity of Lewis acids, relatively low viscosity $\left(65.5 \mathrm{mPa} \times \mathrm{s} \mathrm{w} 25^{\circ} \mathrm{C}\right)$, hydrophobicity and its wide commercial accessibility.

\section{EXPERIMENTAL}

\section{Materials}

1-Butyl-1-methylpyrrolidinium bis(trifluoromethylsulfonyl)imide $\left[\mathrm{C}_{1} \mathrm{C}_{4} \mathrm{Pyrr}\right]\left[\mathrm{NTf}_{2}\right](99 \%)$ was produced by IoLiTec (Germany). Prior to use, it was washed several times with water, and then dried under vacuum at $80^{\circ} \mathrm{C}$, to water content below $100 \mathrm{ppm}$. Metal chlorides $\left(\mathrm{InCl}_{3}\right.$, $\mathrm{ScCl}_{3}, \mathrm{YCl}_{3}, \mathrm{YbCl}_{3}, \mathrm{LaCl}_{3}, \mathrm{BiCl}_{3}, \mathrm{ZnCl}_{2}$ and $\mathrm{CuCl}_{2}$ ) were anhydrous with purity of $99.99 \%$ and were provided by Aldrich. Cyclohexanone (>99\%) - Merck and triethyl orthoformate $(>98 \%)$ - Fluka were used in the reaction without further purification. Toluene pure p.a. (99.5\%) and cyclohexane pure p.a. (99.5\%) were purchased from Chempur.

\section{The general acetalization procedure}

Metal chloride $\left(\mathrm{InCl}_{3}, \mathrm{ScCl}_{3}, \mathrm{YCl}_{3}, \mathrm{YbCl}_{3}, \mathrm{LaCl}_{3}, \mathrm{BiCl}_{3}\right.$, $\mathrm{ZnCl}_{2}$ and $\mathrm{CuCl}_{2}$ ) was weighed in an amount equal to $0.04 \mathrm{mmol}$ in a screw-capped thoroughly dried vial with a capacity of $16 \mathrm{ml}$ and equipped with a magnetic stirrer. Then $1.352 \mathrm{~g}(3.2 \mathrm{mmol})$ of ionic liquid $\left[\mathrm{C}_{1} \mathrm{C}_{4} \mathrm{Pyrr}\right]\left[\mathrm{NTf}_{2}\right]$ was introduced and the vial was flushed by the use of argon and sealed. $\mathrm{InCl}_{3}$ dissolved without the need of prior heating. For other catalysts, the mixture was heated at $60^{\circ} \mathrm{C}$ in order to dissolve the metal chloride. Usually, after 30 minutes clear solution was obtained, with the exception of $\mathrm{CuCl}_{2}$ and $\mathrm{LaCl}_{3}$ which remained solid and dispersed in the ionic liquid. For these two catalysts, a modified dissolution procedure was used. At first copper(II) chloride in ethanol $(40 \mathrm{mg})$, and lanthanum chloride in ethanol-water $(40 \mathrm{mg} / 10 \mathrm{mg})$ mixture were dissolved. Then the ionic liquid was added.

Next, the produced catalyst system was cooled down to $0^{\circ} \mathrm{C}$, and $0.3920 \mathrm{~g}(4 \mathrm{mmol})$ of cyclohexanone and $0.8880 \mathrm{~g}(6 \mathrm{mmol})$ of triethyl orthoformate were inserted into the vial accompanied by stirring. The reaction was carried out in 5 minutes. Then, the product and the unreacted reactants were separated from the catalyst system by extraction with cyclohexane $(6$ and $4 \mathrm{ml})$. The 
combined extracts were analyzed by gas chromatography. Basing on this analysis it was possible to determine the conversion of cyclohexanone and the triethyl orthoformate, as well as the selectivity of cyclohexanone conversion to the product (1,1-diethoxycyclohexane).

For a system consisting of $\mathrm{YbCl}_{3}$ and $\left[\mathrm{C}_{1} \mathrm{C}_{4} \mathrm{Pyrr}\right]\left[\mathrm{NTf}_{2}\right]$ reactions were also carried out with various amounts of ionic liquids (0.676 and $2.028 \mathrm{~g}$ ). Other reaction conditions remained as before.

In the studies on recycling the selected catalyst systems, the reaction was carried out as described above. The solvent residues were removed under the reduced pressure from the lower phase of catalytic system which was left after separating the cyclohexane extract. The substrats were then re-added and the reaction was carried out again in the same conditions as the first synthesis.

\section{Analytical procedure}

The chromatographic analysis was conducted using an apparatus produced by ThermoQuest Italia, model GC 8000 TOP Series, equipped with a column of Rxi®-17 $(30 \mathrm{~m}, 0.53 \mathrm{~mm}, 1.5 \mu \mathrm{m})$. The conditions of the analysis were as follows: carrier gas - He $(4 \mathrm{ml} / \mathrm{min})$, detector FID $\left(260^{\circ} \mathrm{C}\right)$, the injector $\left(250^{\circ} \mathrm{C}\right)$, injection $0.1 \mu \mathrm{l}$, split 1:4. The thermostat temperature was as follows: $50{ }^{\circ} \mathrm{C}(3 \mathrm{~min})-10^{\circ} \mathrm{C} / \mathrm{min}-100^{\circ} \mathrm{C}(3 \mathrm{~min})-10^{\circ} \mathrm{C} / \mathrm{min}$ $-210^{\circ} \mathrm{C}(5 \mathrm{~min})$. The quantitative analysis was based on the method of internal standard (with toluene as the reference) and the internal normalisation method.

\section{Discussion and results}

The presented studies compared the acetalization reactions in the presence of catalyst systems composed of metal chloride $\left(\mathrm{InCl}_{3}, \mathrm{ScCl}_{3}, \mathrm{YCl}_{3}, \mathrm{YbCl}_{3}, \mathrm{LaCl}_{3}\right.$, $\mathrm{BiCl}_{3}, \mathrm{ZnCl}_{2}$ and $\left.\mathrm{CuCl}_{2}\right)$ and ionic liquid - $\left[\mathrm{C}_{1} \mathrm{C}_{4} \mathrm{Pyrr}\right]$ [NTf $f_{2}$. Cyclohexanone (1) and triethyl orthoformate (2) (Fig. 1) were selected as model substrates. 1,1-Diethoxycyclohexane (3) was the main product. As a result of the ethanol molecule release from the product, the 1-ethoxycyclohex-1-en (4) as by-product was created. The reaction was carried out at a molar ratio of metal chloride: (1):(2): [ $\left.\mathrm{C}_{1} \mathrm{C}_{4} \mathrm{Pyrr}\right]\left[\mathrm{NTf}_{2}\right]$ of 1:100:150:80, $0^{\circ} \mathrm{C}$, for 5 minutes.

In the presence of almost all catalytic systems it was possible to obtain high conversions of cyclohexanone (94-99\%) and triethyl orthoformate (75-80\%) (Fig. 2). Selectivities of conversion of cyclohexanone to 1,1-diethoxycyclohexane were also high and ranged between 92 to $97 \%$ (Fig. 3). In the presence of catalyst systems containing $\mathrm{CuCl}_{2}$ or $\mathrm{LaCl}_{3}$, the lower conversions of cyclohexanone (71 and 52\% respectively) and orthoformate (72 and 61\% respectively) were obtained. However, the selectivities were as high (95-97\%) as in the presence of the other metal chlorides. Slightly poorer conversions, in the presence of copper(II) chloride and lanthanum chloride might have been caused by addition ethanol or ethanol-water mixture to form homogenous catalysts system. It should be emphasized that, $\mathrm{CuCl}_{2}$ and $\mathrm{LaCl}_{3}$ were poorly soluble or insoluble in $\left[\mathrm{C}_{1} \mathrm{C}_{4} \mathrm{Pyrr}\right]\left[\mathrm{NTf}_{2}\right]$, due to their high lattice energy. However, ethanol and water caused the solvation of $\mathrm{CuCl}_{2}$ and $\mathrm{LaCl}_{3}$. In solvated form they dissolved in the ionic liquid.

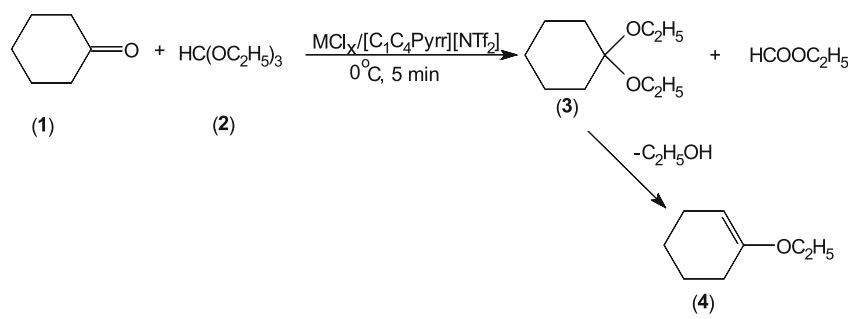

Figure 1. Reactions occurring in the studied system consisting of cyclohexanone (1), triethyl orthoformate (2) and $\mathrm{MCl}_{\mathrm{x}} /\left[\mathrm{C}_{1} \mathrm{C}_{4} \mathrm{Pyrr}\right]\left[\mathrm{NTf}_{2}\right]$

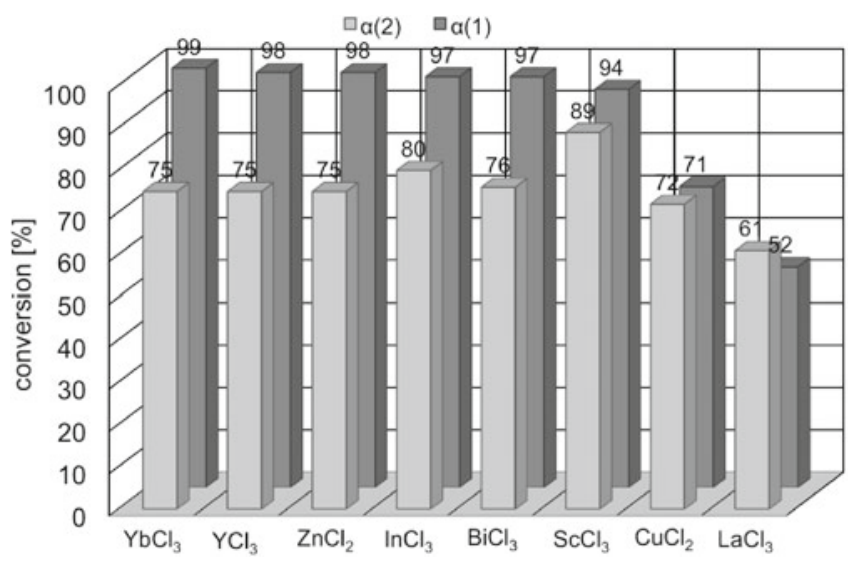

Figure 2. The conversion of cyclohexanone $-\alpha(\mathbf{1})$ and orthoformate $-\alpha(2)$ in an acetalization reaction catalyzed by a metal chloride $/\left[\mathrm{C}_{1} \mathrm{C}_{4}\right.$ Pyrr $]\left[\mathrm{NTf}_{2}\right]$ catalyst system

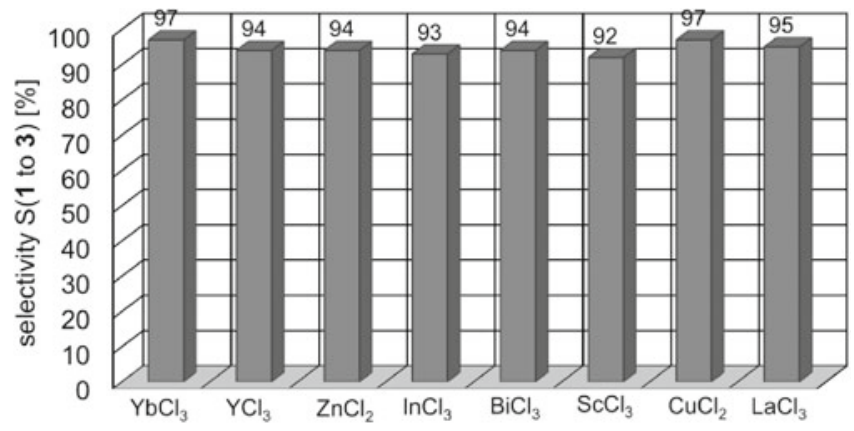

Figure 3. The selectivity of conversion of cyclohexanone (1) to 1,1-diethoxycyclohexane (3) in a reaction catalyzed by a metal chloride $/\left[\mathrm{C}_{1} \mathrm{C}_{4}\right.$ Pyrr $]\left[\mathrm{NTf}_{2}\right]$ catalyst system

The studies on the acetalization reaction at different Lewis acid concentration levels in ionic liquid were carried out basing on the system containing $\mathrm{YbCl}_{3}$. The molar ratio of metal chloride: $\left[\mathrm{C}_{1} \mathrm{C}_{4} \mathrm{Pyrr}\right]\left[\mathrm{NTf}_{2}\right]$ was $1: 40,1: 80,1: 120$. The best results were obtained for the concentration of 1:80 $(\mathrm{mol} / \mathrm{mol})$. Using higher concentration of ytterbium chloride (1:40) gave lower selectivity of cyclohexanone conversion $(82 \%)$ to the product (3). Lower concentration (1:120) on the other hand, decreased the substrate conversion and the product yield. Moreover it was necessary to use a larger amount of cyclohexane, to complete extraction of the reactants from the catalyst system, after the reaction.

For selected catalyst systems the recycling experiments were conducted (Figs. 4 and 5). The products and the unreacted substrates were separated from the catalyst systems consisting of ionic liquid and the metal chloride, by the extraction with cyclohexane. It was found that even after five time use the same sample of ytterbium chloride (Fig. 4) or indium chloride (Fig. 5) dissolved in the ionic liquid, it is possible to obtain high substra- 


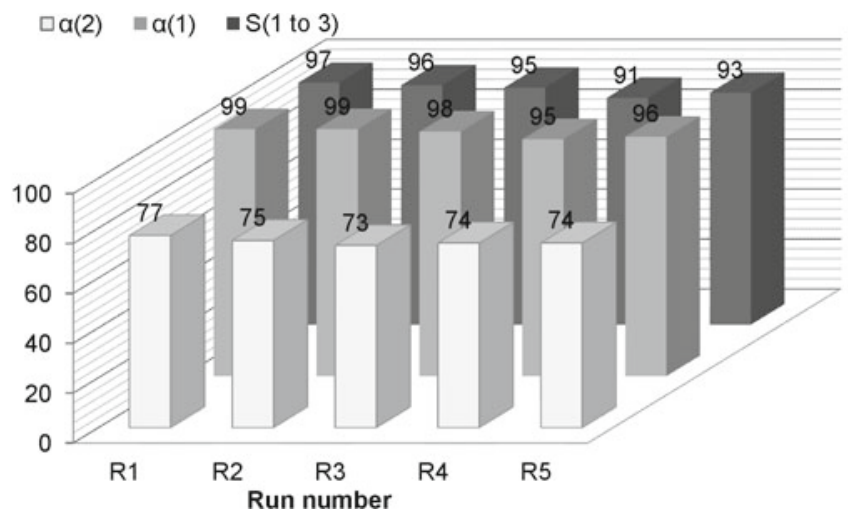

Figure 4. The conversion of cyclohexanone $-\alpha(\mathbf{1})$, orthoformate $-\alpha(2)$ and selectivity $-\mathrm{S}(\mathbf{1}$ to $\mathbf{3})$ in subsequent reaction runs of the same sample of $\mathrm{YbCl}_{3} /\left[\mathrm{C}_{1} \mathrm{C}_{4} \mathrm{Pyrr}\right]$ $\left[\mathrm{NTf}_{2}\right]$ system

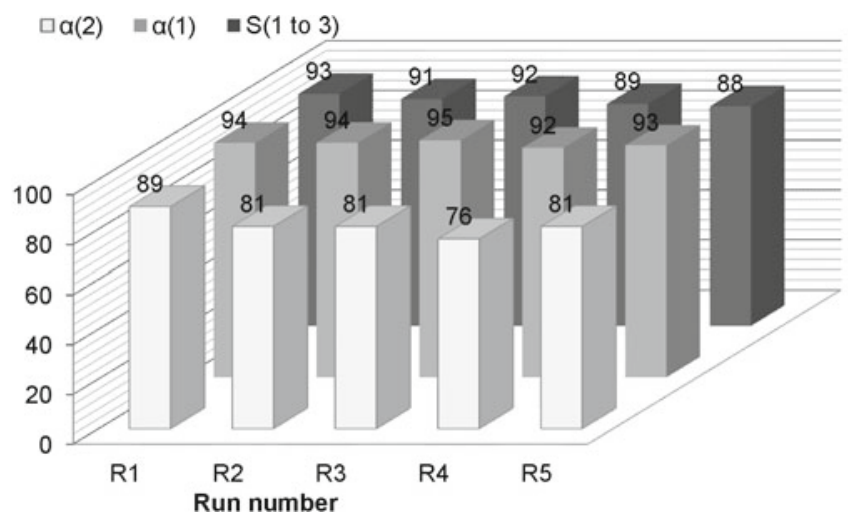

Figure 5. The conversion of cyclohexanone $-\alpha(\mathbf{1})$, orthoformate $-\alpha(2)$ and selectivity $-\mathrm{S}(\mathbf{1}$ to $\mathbf{3})$ in subsequent reaction runs of the same sample of $\mathrm{InCl}_{3} /\left[\mathrm{C}_{1} \mathrm{C}_{4}\right.$ Pyrr $]$ $\left[\mathrm{NTf}_{2}\right]$ system

tes conversions and high selectivity of cyclohexanone conversion to 1,1-diethoxycyclohexane. Thus, the metal chlorides were effectively immobilized in the ionic liquid. Due to high hydrophobicity of the used ionic liquid, it "protected" the metal chloride against moisture and allowed for it to be re-used.

\section{CONCLUSIONS}

Almost all metal chlorides dissolved in pyrrolidinium ionic liquid creating a catalyst system. Poor solubility of copper(II) chloride and lanthanum chloride in the ionic liquid resulted from the high lattice energy of these compounds. To create the homogeneous catalyst system of $\mathrm{CuCl}_{2}$ and $\mathrm{LaCl}_{3}$ in the $\left[\mathrm{C}_{1} \mathrm{C}_{4}\right.$ Pyrr $]\left[\mathrm{NTf}_{2}\right]$ the addition of ethanol or ethanol-water mixture was needed. As a consequence of this, the substrates conversions were lower when $\mathrm{CuCl}_{2}$ or $\mathrm{LaCl}_{3}$ were used. Other metal chlorides - $\mathrm{InCl}_{3}, \mathrm{ScCl}_{3}, \mathrm{YCl}_{3}, \mathrm{YbCl}_{3}, \mathrm{BiCl}_{3}$ and $\mathrm{ZnCl}_{2}$, in combination with pyrrolidinium ionic liquid, in the studied reaction showed higher substrates conversions. In the presence of all catalytic systems it was possible to obtain 1,1-diethoxycyclohexane with high selectivity. The metal chlorides used are Lewis acids, and are inactivated by water and by solvents which strongly coordinate the metal atom. In the environment of $\left[\mathrm{C}_{1} \mathrm{C}_{4} \mathrm{Pyrr}\right]\left[\mathrm{NTf}_{2}\right]$ the metal chlorides were active due to the hydrophobicity of the ionic liquid, and due to the weak coordination of the metal atom by anion $\mathrm{NTf}_{2}$ of the ionic liquid.
The product could be easily separated by cyclohexane extraction from a Lewis acid immobilized in the ionic liquid. Moreover, immobilizing the metal chloride in ionic liquid allowed for its recycling. Even after the repeated use the substrates conversions, and the reaction selectivity remained almost unchanged.

Studies on the catalytic activity of the obtained systems metal chloride/[ $\left.\mathrm{C}_{1} \mathrm{C}_{4} \mathrm{Pyrr}\right]\left[\mathrm{NTf}_{2}\right]$ in synthesis of various acetals are in progress.

\section{LITERATURE CITED}

1. Closson, A.P. \& Monteleone, M.G. (2010). U.S. Patent No. 7820616.

2. Bickers, D.R., Calow, P., Greim, H.A., Hanifin, J.M., Rogers, A.E., Saurat, J.H., Sipes, I.G., Smith, R.L. \& Tagami, H. (2003). The safety assessment of fragrance materials. Regulatory Toxicology and Pharmacology 37, 218-273. DOI: 10.1016/ S0273-2300(03)00003-5.

3. Sato, H. \& Shishikura, A. (2012). U.S. Patent No. 8158564.

4. Delfort, B., Durand, I., Jaecker, A., Lacome, T., Montagne, X. \& Paille, F. (2006). U.S. Patent No. 7097674.

5. Pauley, E.P. \& Neighbor, K.S. (2003). U.S. Patent No. 6512146.

6. Boutique, J.P., Burckett St., Laurent, J.Ch., Bouilliche, M., Beckholt, D.A., Murthy, S.R. \& Tremblay, M.E. (2012). U.S. Patent No. 8293697.

7. Butora, G., Koeplinger, K.A., MacCoss, M., McMasters, D.R., Olsen, D.B. \& Yang, L. (2009). U.S. Patent No. 7632821.

8. Smith, B.M. \& Graham, A.E. (2006). Indium triflate mediated acetalization of aldehydes and ketones. Tetrahedron Lett. 47, 9317-9319. DOI: 10.1016/j.tetlet.2006.10.111.

9. Yip, L., Kubczyk, T.M., Davies, T.E., Taylor, S.H., Apperley, D.C. \& Graham, A.E. (2012). Nanoporous aluminosilicate mediated transacetalization reactions: application in glycerol valorization. Catal. Sci. Technol. 2, 2258-2263. DOI: 10.1039/ c2cy20188g.

10. Kim, S., Chin, C.S. \& Eum, M.S. (2006). Cyclic acetals from catalytic addition of diols to terminal alkynes with a cationic iridium complex containing two labile ligands. J. Mol. Catal. A: Chem. 253, 245-248. DOI: 10.1016/j.molcata.2006.03.010.

11. Krompiec, S., Penkala, M., Szczubiałka, K. \& Kowalska, E. (2012). Transition metal compounds and complexes as catalysts in synthesis of acetals and orthoesters: Theoretical, mechanistic and practical aspects. Coordin. Chem. Rev. 256, 2057-2095. DOI: 10.1016/j.ccr.2012.05.006.

12. Janus, E. \& Stefaniak, W. (2008). The Diels-Alder reaction in phosphonium ionic liquid catalysed by metal chlorides, triflates and triflimides. Catal. Lett. 124, 105-110. DOI: 10.2478/ v10026-010-0015-0.

13. Janus, E. \& Bittner, B. (2010). Triethylsulfonium Bistriflimide as the reaction medium in catalyzed and uncatalyzed cycloaddition [4+2]. Catal. Lett. 324, 147-154. DOI: 10.1007/ s10562-009-0211-9.

14. Kim, Y.J. \& Varma, R.S. (2005). Microwave-assisted preparation of 1-butyl-3-methylimidazolium tetrachlorogallate and its catalytic use in acetal formation under mild conditions. Tetrahedron Lett. 46, 7447-7449. DOI: 10.1016/j.tetlet.2005.08.059. 